\title{
The effect of eight weeks of aerobic exercise with moderate and high intensities on serum irisin and PGC-1 $\alpha$ protein levels in obese male Wistar rats
}

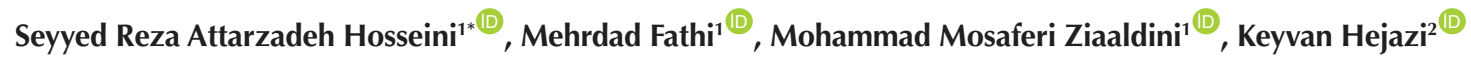 \\ ${ }^{1}$ Department of Sport Sciences, Ferdowsi University of Mashhad, Mashhad, Iran \\ ${ }^{2}$ Department of Sport Sciences, Hakim Sabzevari University, Sabzevar, Iran
}

*Corresponding Author: Seyyed Reza Attarzadeh Hosseini, Paradise Daneshgah, Azadi Square, Faculty of Physical Education and Sport Sciences, Ferdowsi University of Mashhad, Mashhad, Iran. Postal code: 91779-48979; Po BOX: 1574; Tel: +98 (51) 38833910; Fax: +98 (51) 38829580; Email: attarzadeh@um.ac.ir

\begin{abstract}
Background and aims: Irisin myokine whose secretion is induced by exercise is associated with an increase in thermogenesis. However, the effect of aerobic exercise with different intensities on the production and release of irisin in overweight individuals is controversial. This study aimed to investigate the effect of eight weeks of aerobic training with different intensities on PGC- $1 \alpha$, FNDC5, UCP1, and irisin in obese male Wistar rats.

Methods: In this experimental study, 24 adult obese male Wistar rats (weight: 250-300 g; body mass index [BMI] >30 g/cm2) divided into three groups, including aerobic training with $28 \mathrm{~m} / \mathrm{min}$ (moderate intensity [MI]), aerobic training with $34 \mathrm{~m} / \mathrm{min}$ (high intensity [HI]), and control. All training groups exercised for eight weeks walking on a treadmill (five 60-min sessions per week). The paired sample $t$ test and one-way ANOVA were used to determine the intra- and inter-group differences. Furthermore, Tukey's post hoc test was used.

Results: The levels of PGC- $1 \alpha$ in muscle tissue in aerobic training groups with $\mathrm{MI}$ and $\mathrm{HI}$ increased $(P=0.001$ and $\mathrm{F}=11.81)$ compared to control group. The levels of irisin $(P=0.006$ and $\mathrm{F}=6.10)$ and $\mathrm{UCP1}(P=0.04)$ were significantly increased in MI group. On the other hand, FNDC5 increased significantly in both $\mathrm{MI}$ and $\mathrm{HI}$ groups $(P=0.001$ and $\mathrm{F}=12.49)$. While irisin and UCP1 levels increased in $\mathrm{HI}$ group compared to the control group, the change was not statistically significant $(P>0.05)$. The levels of irisin, $U C P 1$, and FNDC5 increased more significantly in $\mathrm{Ml}$ group than in $\mathrm{HI}$ group $(P<0.05)$.

Conclusion: Both types of aerobic training ( $\mathrm{MI}$ and $\mathrm{HI}$ ) had a beneficial effect on changes in irisin, UCP1, FNDC5, and PGC- $1 \alpha$ levels. Accordingly, moderate exercise possibly changes the phenotype of white to brown adipose tissue leading to an increase in thermogenesis, body weight loss, and sensitivity to insulin.

Keywords: Aerobic training, Myokine, PGC- $1 \alpha$, Irisin
\end{abstract}

Received: 19 May 2020, Accepted: 27 June 2020, ePublished: 30 March 2021

\section{Introduction}

Studies have shown that irisin hormone, as a mediator of skeletal and fat muscle tissue, facilitates the conversion of white adipose tissue to brown (1). The contraction of the skeletal muscle increases the stimulation of various protein signals, such as peroxisome proliferator-activated receptors (PPARs) alpha or PGC- $1 \alpha$ and its secretion agents, myokines (2). Physical activity, by stimulating the physiological activities in skeletal muscle, increases the expression of PGC-1 $\alpha$ gene and subsequently, membrane protein of fibronectin or FNDC5 in skeletal muscle; this ultimately leads to the production of irisin and can apply its biological effects on energy metabolism (3). Physical activity increases the PGC- $1 \alpha$ and thus promotes a number of functions including: mitochondrial biogenesis, fatty acid oxidation (lipogenesis), angiogenesis stimulation, and reduction of pre-inflammatory cytokines.
These changes increase exercise capacity, alter the type of twitch fibers, and prevent muscle atrophy(4). It seems that skeletal muscle creates many of these adaptations from exercise in interaction with adipose tissue (5). The mechanism by which physical activity can increase PGC$1 \alpha$ in the skeletal muscle and have beneficial effects on other organs is still unclear. One assumption is that the muscles involved in exercises with the release of myokines, circulating proteins, play a role in energy metabolism (2, 6).

Irisin is a kind of protein with a molecular weight of 12 $\mathrm{kDa}$, consisting of 112 amino acids; and it was identified as a myokines in 2012. Irisin is the product of the cleavage of the FNDC5 gene, that is a type of membrane protein mainly found in the muscle tissue of humans and mice, where it can be released into the plasma (7). The expression of FNDC5 gene increases through the mediation of 
PPAR- $\gamma$ and PGC- $1 \alpha$. FNDC5 gene encodes UCP1, that is promoted by muscle activity and affects the production process of irisin (7). Irisin increases the expression of UCP1 gene in white adipose tissue, which is a characteristic gene of brown adipose tissue and increases the oxidation of fatty acids, and thus thermogenesis. Therefore, irisin changes the white adipose tissue into brown adipose tissue, resulting in increased thermogenesis, energy consumption, glucose homeostasis, and ultimately weight loss (7).

Although there is a consensus on the importance of physical activity and many studies have shown its effective role as a low-cost solution to tackle the prevalence of obesity and overweight $(8,9)$, the type and intensity of exercise to develop physical health is still unclear. The results of research on the effect of aerobic exercise on the levels of irisin and PGC-1 $\alpha$ are contradictory. For example, some cases $(10,11)$ reported an increase $(7,12)$ in irisin and PGC$1 \alpha$ levels. Hoshino et al (13) examined the effect of intense periodic exercises (10 moves, 1 minute with an intensity of $30-55 \mathrm{~m} / \mathrm{min}, 2$ minutes break, for 4 weeks, and 5 days a week) on the oxidation of fatty acids in mitochondria in the white and red muscle tissues, and concluded that the protein PGC-1 $\alpha$ increased in red (22\%) and white muscle tissues (16\%), but the receptor interacting protein-140 (RIP-140) did not change significantly. Shirvani and Aslani (14) investigated the effect of two types of exercise (medium and severe periodic) on serum irisin levels and expression of PGC- $1 \alpha$ gene expression in muscle tissue of 32 male Wistar rats, and concluded that the expression of PGC-1 $\alpha$ gene expression significantly increased in both groups compared to control group; but serum levels of irisin had no significant difference.

A huge body of evidence shows that exercise can activate brown adipose tissue for prevention and treatment of obesity. While some studies have shown a significant relationship between irisin levels and physical activity and exercise, others have reported an insignificant relationship. These contradictory results could originate from differences in research methodologies. Nevertheless, assuming that irisin, FNDC5, UCP1, and PGC-1 $\alpha$ are among the factors that can activate brown adipose tissue and have anti-obesity effects, no research has been done so far to simultaneously study the effect of different aerobic exercise intensities on irisin, FNDC5, and UCP1 variations. Therefore, the current study aimed to compare the effect of aerobic exercise with different intensities on irisin, FNDC5, UCP1, and PGC- $1 \alpha$ levels and find out which intensity or a combination of intensities can stimulate the variations of some of myokine levels and adipose tissue in obese Wistar rats.

\section{Materials and Methods Animals}

A total of 24 male Wistar rats (8 weeks old) (weight range: $250-300 \mathrm{~g}$; body mass index $[\mathrm{BMI}]>30 \mathrm{~g} / \mathrm{cm}^{2}$ ) were purchased from the Razi Vaccine \& Serum Research Institute of Iran. After adaptation to the new standard environment for at least two weeks (temperature $23 \pm 1^{\circ} \mathrm{C}$, humidity $50 \pm 3 \%$, and 12 -hour light/12-hour lightdark cycle with free access to food and water). After two weeks of familiarity with lab environment, the rats were randomly assigned to three equal groups $(\mathrm{n}=8$ in each group). The groups were as follows: Group 1: moderateintensity (MI) aerobic exercise, Group 2: high-intensity (HI) aerobic exercise, and control.

\section{Induced Obesity Rat}

The obese group had a high-fat diet containing more calories and fat than standard food (energy of 4.8 vs. 3.9 $\mathrm{kcal}$ in $\mathrm{g}$ and fat of $39 \%$ vs. 3.5\%). All rats were fed in this way for 14 weeks and had free access to water and food throughout this phase of the study (Table 1).

\section{Measurement of PGC-10, FNDC5, UCP1, and Irisin Levels}

After 48 hours from the last exercise session, blood samples, adipose and muscle tissues were collected. After animal anesthetizing by a combination of Ketamine (30$50 \mathrm{mg} / \mathrm{kg}$ of body weight) and xylazine $(3-5 \mathrm{mg} / \mathrm{kg}$ of body weight), $5 \mathrm{ml}$ of blood was taken from the heart of the rats (15). The samples were centrifuged at $3000 \mathrm{rpm}$ for 15 minutes at $4^{\circ} \mathrm{C}$. After blood collection, a 5 to $6 \mathrm{~cm}$ long cut was made in the abdominal region, and soleus muscles were quickly removed, washed in normal saline solution, transferred to a $1.5 \mathrm{~mL}$ micro tube and placed immediately in liquid nitrogen and kept in a freezer at $-80^{\circ} \mathrm{C}$ for further analysis (15).

After extracting the tissue samples from the freezer, they were poured into the pounder and smashed with liquid nitrogen. The produced powder was then transferred to a homogenizer tube and combined with a radioimmunoprecipitation assay (RIPA) buffer solution and mixed with a homogenizer (Potter Elvejheim) set at $800 \mathrm{rpm}$ and cooled with ice. Finally, the sample was extracted from the tube via a sampler and poured into a micro tube of $1.5 \mathrm{~mL}$. The micro tube was centrifuged for 20 minutes at a speed of $20000 \mathrm{rpm}$ at $4^{\circ} \mathrm{C}$. After centrifuging, supernatants were removed and transferred

Table 1. High-fat and standard food content

\begin{tabular}{lcccccccccccccccccc}
\hline Contents & Protein & Fat & Carbohydrate & Fiber & Ash Calcium & Phosphorus & Salt & Humidity & Lysine & $\begin{array}{c}\text { Methionine } \\
\text { Methionine } \\
+ \text { cysteine }\end{array}$ & $\begin{array}{c}\text { Threonine }+\begin{array}{c}\text { Other } \\
\text { Tryptophan } \\
\text { materials }\end{array} \\
\text { Kcal energy } \\
\text { in grams }\end{array}$ \\
\hline High fat (\%) & 18 & 39 & 20 & 2 & 1 & 1 & 0.7 & 0.5 & 5 & 1.15 & 0.33 & 0.63 & 0.95 & 10 \\
Standard (\%) & 20 & 3.5 & 25 & 14.5 & 10 & 1 & 0.7 & 0.5 & 10 & 1.15 & 0.33 & 0.63 & 0.95 & 11 & 3.9 \\
\hline
\end{tabular}


to a new micro tube and the samples were kept in the freezer at $-80^{\circ} \mathrm{C}$. The irisin, PGC- $1 \alpha$, UCP1, and FNDC5 levels were measured by a special Rat ELISA Kit (EASTBIOPHARM, licensed by the US).

\section{Familiarization stage and exercise protocol}

The study lasted for eight weeks, with a frequency of 5 sessions per week and 60 minutes per session at different speeds on treadmill. After an adaptation period, in the first week, the rats were placed on the rodent motor-driven treadmill to walk at a speed of $10 \mathrm{~m} / \mathrm{min}$ with a 00 slope for 15 minutes. During the second and third weeks, the speed and duration of the exercise were gradually increased (HI: $34 \mathrm{~m} / \mathrm{min} \sim 80 \%-85 \% \mathrm{VO}_{2} \max$ and $\mathrm{MI}: 28 \mathrm{~m} / \mathrm{min}$ $\left.\sim 70 \%-75 \% \mathrm{VO}_{2} \max \right)$. The exercise volumes in $\mathrm{MI}$ and HI groups were $8.4 \mathrm{~km} /$ wk and $10.2 \mathrm{~km} / \mathrm{wk}$, respectively (16), and finally, 5 minutes of cool down (Table 2).

\section{Statistical Analysis}

After determining the normality of data by ShapiroWilk test and the homogeneity of variances by Levene's test, paired sample $t$ test, one-way ANOVA, and posthoc Tukey tests were employed for analyzing the data and investigating the differences between the groups. Moreover, the collected data were analyzed by SPSS 16.0. Data were presented as mean \pm SEM, and $P<0.05$ was considered to be statistically significant.

\section{Results}

According to Table 3, there was no difference between the protein concentration of UCP1 in adipose tissue of obese male Wistar rats after eight weeks of moderate- and high-intensity aerobic exercises $(P=0.05$ and $\mathrm{F}=3.28)$. However, there was a significant difference between the groups on serum irisin protein $(P=0.006$ and $\mathrm{F}=6.10)$ and the FNDC5 protein levels of muscle tissue in obese male Wistar rats $(P=0.001$ and $\mathrm{F}=12.49)$. Based on the results of Tukey's post hoc test, there was a significant difference between mean concentrations of UCP1 in adipose tissue of the moderate intensity group compare to the control group $(P=0.04)$; however, FNDC5 protein in muscle tissue in the high-intensity group increased significantly compared to the control group $(P=0.04)$ and between moderate intensity compared to the control group have a significant difference $(P=0.02)$.

According to Figure 1, there was no difference between

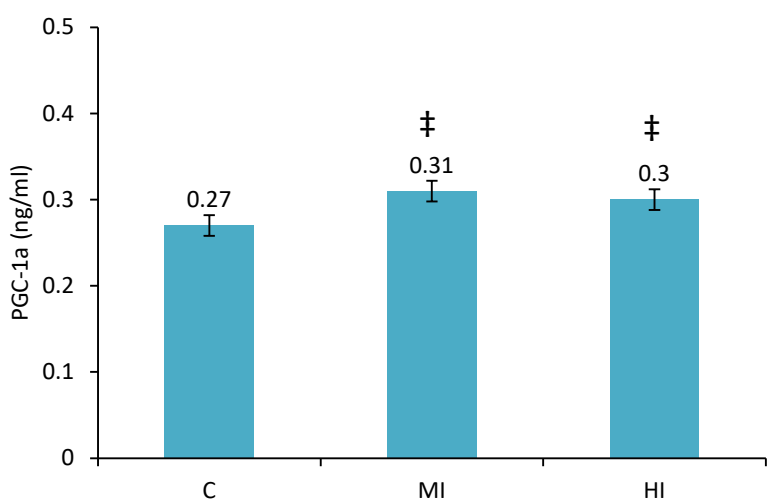

Figure 1. Changes of PGC-1 $\alpha$ levels in different groups. Values are expressed as $\mathrm{M} \pm \mathrm{SD}$. $\mathrm{Ml}$ : continuous moderate exercise, $\mathrm{HI}$ : highintensity aerobic exercise, C: control. ${ }^{*} P<0.05$ vs. baseline ₹ Significant level compared to the control group

the concentration of peroxisome proliferator-activated receptor gamma coactivator 1 -alpha (PGC-1a) in the muscle tissue of male Wistar rats among $\mathrm{MI}$ and $\mathrm{HI}$ groups $(P=0.23$ and $\mathrm{F}=0.78)$. Based on the results of Tukey's post hoc test, there was a significant difference between mean concentrations of PPAR- $\gamma$ coactivator in the muscle tissue of MI and HI groups with the control group $(P=0.001$ and $\mathrm{F}=11.81)$. Serum irisin level was significantly increased $(16.44 \%)$ in the MI group compared to control $(6.23 \pm 0.21 ; P=0.001)$, while the irisin levels in the HI group increased by $7.10 \%$ compared to control group, though it was not statistically significant $(5.73 \pm 0.64$ vs 5.35 \pm 0.62$)(P=0.17)$ (Figure 2). According to Table 4, intra-group differences in mean body weight in control group increased significantly $(P=0.001)$ and decreased significantly in $\mathrm{MI}$ and HI groups $(P=0.001)$. Based on the results of Tukey's post hoc test, there was a significant difference between the MI and control groups $(P=0.001)$, and between the HI and control groups $(P=0.001)$.

\section{Discussion}

This study aimed to compare the effect of 8-week aerobic

Table 3. The variation of UCP1 and FNDC5 proteins in experimental and control groups after eight weeks of aerobic exercise

\begin{tabular}{lccc}
\hline Variable & $\begin{array}{c}\text { C } \\
\text { (Mean } \pm \text { SD) }\end{array}$ & $\begin{array}{c}\text { MI } \\
(\text { Mean } \pm \text { SD) }\end{array}$ & $\begin{array}{c}\text { HI } \\
(\text { Mean } \pm \text { SD })\end{array}$ \\
\hline UCP1 $(\mathrm{ng} / \mathrm{mL})$ & $5.46 \pm 0.36$ & $5.82 \pm 0.31^{\mathrm{a}}$ & $5.59 \pm 0.37$ \\
FNDC5 $(\mathrm{ng} / \mathrm{mL})$ & $39.56 \pm 1.72$ & $48.24 \pm 6.68^{\mathrm{a}}$ & $41.85 \pm 1.87^{\mathrm{a}}$
\end{tabular}

MI: continuous moderate exercise, $\mathrm{HI}$ : high-intensity aerobic exercise, C: control.

a The mean difference is significant at 0.05 .

Table 2. Moderate and high-intensity aerobic exercise protocol on treadmill

\begin{tabular}{lllllllll}
\hline Groups/Weeks & & $\mathbf{1}$ & $\mathbf{2}$ & $\mathbf{3}$ & $\mathbf{4}$ & $\mathbf{5}$ & $\mathbf{6}$ & $\mathbf{7}$ \\
\hline \multirow{2}{*}{$\mathrm{MI}$} & Duration (min) & 15 & 27 & 34 & 40 & 46 & 52 & 58 \\
& Speed (m/min) & 10 & 15 & 20 & 21 & 23 & 24 & 26 \\
$\mathrm{HI}$ & Duration (min) & 15 & 27 & 35 & 45 & 54 & 59 & 60 \\
& Speed (m/min) & 10 & 15 & 20 & 22 & 24 & 27 \\
\hline
\end{tabular}

MI: Moderate-intensity aerobic exercise, HI: high-intensity aerobic exercise 


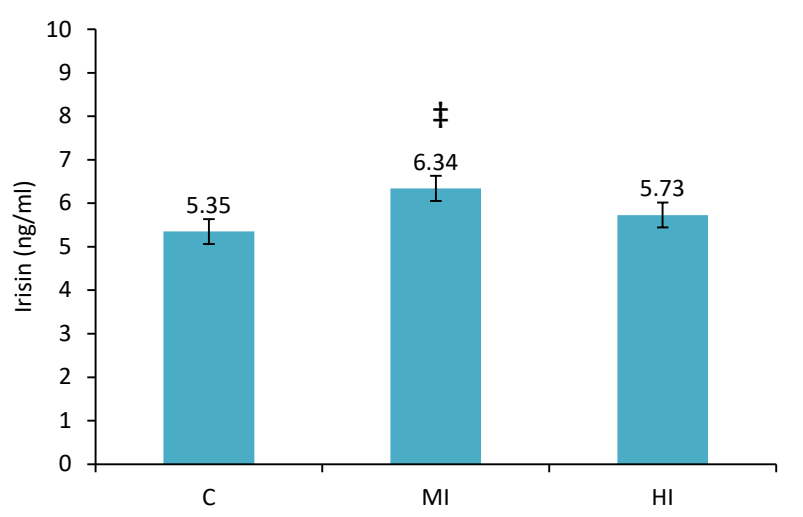

Figure 2. Changes of Irisin levels in different groups. Values are expressed as $\mathrm{M} \pm \mathrm{SD}$. MI: continuous moderate exercise, $\mathrm{HI}$ : highintensity aerobic exercise, $C$ : control. ${ }^{*} P<0.05$ vs. baseline. ₹ Significant level compared to the control group

exercise with two different intensities on PGC-1 $\alpha$ levels of muscle tissue and serum irisin in fat male Wistar rats. According to the results of the present study, there was a significant increase in the concentration of PPAR- $\gamma$ coactivator $1-\alpha(\mathrm{PGC1} \alpha)$ protein in the muscular tissue of obese male Wistar rats in the MI and HI groups compared with the control group. The reason for the difference in findings may be attributed to different subjects in research that were diabetic or obese rats. Also, these differences can be related to different exercise protocols, including volume and severity and type of exercise program, measurement methods of the indicators, or differences in the level of plasma or serum levels.

The mechanisms by which PGC- $1 \alpha$ activates the expression of the gene is not well known. The results of the studies indicate that the activity of acetyl transfer (CBP/P300, SRC-1) is activated. In addition, Terminal $\mathrm{C}$ include the SR motif and the RNA binding region. This region should stimulate the expression of specific endogenous genes and interact with the proteins involved in the processing of RNA and the TRAP complex involved in the initiation of transcription (17). Moreover, PGC- $1 \alpha$ is associated with two other transcriptional complexes with acetyl transfer activity including GCN5 and TIP60. GCN5 secretes PGC-1 $\alpha$ in the lysine residue directly, thereby reducing the PGC-1 $\alpha$ transcription activity. On the other hand, SIRT1 increases the function of this cofactor by pseudizing the PGC- $1 \alpha$. By activating SIRT1, mitochondrial biogenesis, free radical production,

Table 4. The variation of weight in experimental and control groups after eight weeks of aerobic exercise

\begin{tabular}{lcccc}
\hline Variable & Stages & $\begin{array}{c}\text { C } \\
(\text { Mean } \pm \text { SD })\end{array}$ & $\begin{array}{c}\text { MI } \\
(\text { Mean } \pm \text { SD })\end{array}$ & $\begin{array}{c}\text { HI } \\
(\text { Mean } \pm \text { SD })\end{array}$ \\
\hline \multirow{2}{*}{ Weight $(g)$} & Pre-test & $295.75 \pm 1.81$ & $295.16 \pm 1.40$ & $295.41 \pm 2.15$ \\
& Pos-test & $302.58 \pm 1.16^{\mathrm{a}}$ & $287.41 \pm 4.25^{\mathrm{a}, \mathrm{b}}$ & $287.08 \pm 4.23^{\mathrm{a}, \mathrm{b}}$ \\
\hline
\end{tabular}

C: control, MI: continuous moderate exercise, $\mathrm{HI}$ : high-intensity aerobic exercise.

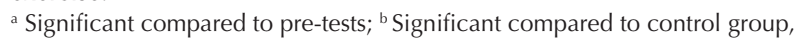

and oxidation of fatty acids are controlled by activating PGC-1 $\alpha$ (18). It is believed that two factors of nutrition and hormonal messages affect the PGC-1 $\alpha$ levels (19). Researchers believe that reducing glucose and increasing glucagon hormone, catecholamine, and glucocorticoid hormones trigger SIRT1 activation and increase the oxidation of mitochondrial fatty acids by activating PPAR (20). Regular long-term exercises seem to positively regulate SIRT1 and PGC-1 $\alpha$ indices (21-23). SIRT1 can activate PGC- $1 \alpha$, which activates PPAR- $\gamma$ activation and lipid oxidation. PGC- $1 \alpha$ induces the expression RNA of UCP2 peak in a PPAR- $\gamma$-dependent behavior. The effects of IL-15 on glycolic and oxidative muscles are different. Conversion of glycolytic to oxidative wires may be a factor in the oxidation of lower hypertrophy (24). The expression of SIRT1 during fructose and the increase of IL-15 protein in various biological processes, including inhibition of apoptosis, increased insulin sensitivity, and the conversion of glycolytic metabolism to aerobic metabolism are involved. However, SIRT1 inhibits muscle differentiation and myofibrillar protein expression. Therefore, the IL-15 and SIRT1 path are active in catabolic conditions and have negative effects on hypertrophy and muscle cell production (25). One of the cellular changes that occurs due to physical activity is the activation of the path of AMPK and p38 via the SIRT1 path, leading to the activation of PGC- $1 \alpha$ and mitochondrial biogenesis (26). The activation of AMPK and SIRT1 is strongly associated with the induction of PGC- $1 \alpha$, and therefore mitochondrial biogenesis. These effects are the result of AMPK's ability to increase the levels of SIRT1 and NAD + activating cells, which triggers SIRT1 activation and allows PGC- $1 \alpha$ to be distillated and affect other downstream pathways in rat muscle. AMPK subunit genetic damage Gamma-sensitive AMP in the muscle damages NAD + . Therefore, activation of PGC- $1 \alpha$ pathway to AMPK is dependent on activation of SIRT1 via $A M P$-sensitive in NAD + (27).

Based on the results of the present study, the serum irisin levels in both MI and HI groups were significantly increased compared to the control group, but these changes were not statistically significant. The FNDC5 protein is cleaved and secreted as a new hormone called irisin(7). FNDC 5 mRNA is more pronounced in muscle than other limbs (28), and expression of FNDC5 in skeletal muscle is significantly associated with the levels of irisin circulation in blood (29). The expression of FNDC5 in skeletal muscle in rats increased with PGC- $1 \alpha$ and decreased in muscle by eliminating PGC- $1 \alpha$ muscle (7). Therefore, a strong relationship is shown between levels of FNDC5 and FNDC5 mRNAs in skeletal muscle $(30,31)$, which supports the role of PGC- $1 \alpha$ as a regulator of FNDC5 and irisin. However, in the present study, MI aerobic exercise may have triggered activation of effective signaling effects on PGC-1 $\alpha$ expression stimulation (32), which resulted in FNDC5 expression and a significant increase in serum 
irisin in PGC-1 $\alpha$. There is a correlation between the changes in the level of irisin and lactate, and both of them increase by intense physical activity; it is suggested that a high rise in the amount of irisin is due to the amount of muscle need for energy.

Our results showed that the MI aerobic exercise program resulted in a more significant increase in the level of UCP1 protein in adipose tissue of obese male rats compared to $\mathrm{HI}$ aerobic exercise. Physical activity causes the norepinephrine hormone to increase the expression of UCP1 and PGC$1 \alpha$ in adipose tissue through the stimulation of cAMPdependent pathways and beta-adrenergic receptors (33). Probably, the increase in norepinephrine can be one of the influential factors in UCP1 in subcutaneous fat. On the other hand, irisin hormone is the main stimulant for enhancing the expression of UCP1 and the thermogenesis capacity of adipose tissue. Hence, the increased level of irisin due to exercise causes the expression of UCP1 mRNA in white adipose cells by activating PPAR-a, changes white adipose tissue to brown adipose tissue, and increases energy expenditure through thermogenesis (7).

Since irisin level was significantly increased in MI group in the current study, the main reason for enhancing UCP1 in subcutaneous fat can be attributed to changes in irisin level. One of the other most influential factors in UCP1 expression is the expression of PGC-1 $\alpha$ (34). Activation of brown adipose tissue and subsequent activation of UCP1 is controlled by hypothalamus, which can be caused by the release of norepinephrine by the sympathetic nervous system, which in itself stimulates the function of brown adipose tissue (35). This process results in the hydrolysis of triglycerides stored in small fat droplets and the activation of free fatty acids UCP1. Like white adipose, this neurotransmitter activates hormone-sensitive lipase found in adipose cells and activates the hydrolysis of triglycerides to fatty acids and glycerol. However, unlike white adipose, free fatty acids released from multihypophyseal adipocytes are rapidly metabolized and, with increasing oxygen consumption and thermogenesis, the increase in temperature in the tissue causes the warming of local cerebral blood flow, consequently spreading heat throughout the body. Therefore, the temperature of the tissue and circulating blood are increased. Heat production in these cells increases due to the presence of a membrane protein called UCP1 in the inner membrane of the mitochondria. UCP1 provides the possibility of the return of the protons that have already been transmitted to the mid-membrane space without passing through the ATP synthase complex. As a result, the energy generated by the proton leakage is released in the form of heat to warm up the blood stream (36).

One of the limitations of this study was the inability to test the expression of the gene expression of the PGC$1 \alpha$ mRNA. Also, PGC- $1 \alpha$ values in lipid tissues of different parts of the rats' body, such as subcutaneous and intraperitoneal adipose tissue, were not accepted. Thus, the researcher compared the levels of PGC-1 $\alpha$ in adipose tissue and muscle tissue. Furthermore, the side effects on the signaling cascade did not measure the conversion of white to brown adipose tissue.

\section{Conclusion}

Based on the results of this experimental study, the levels of serum irisin protein, UCP1 in the adipose tissue, and FNDC5 and PGC-1 $\alpha$ in the muscle tissue of obese Wistar rats increased significantly in MI group compared to HI group. It seems that aerobic exercise with different intensities can have a good effect on these factors. Irisin is affected by a variety of sports activities, plays a role in the conversion of white to brown adipose tissue, and contributes to weight loss and increased thermogenesis. However, the irisin response to a variety of sports activities with different intensities requires further research.

Conflict of Interests

The authors declared no conflict of interests.

Ethical Approval

The research was approved by the Ethics Committee of Ferdowsi University of Mashhad, Iran (Code IR.MUMS.REC.2016.131).

Authors' Contributions

Conceptualization and writing the original draft: SRAH and $\mathrm{KH}$; Methodology: SRAH, KH, MF and MMZ; Investigation and writing review \& editing: $\mathrm{KH}, \mathrm{MF}$ and $\mathrm{MMZ}$.

\section{Funding/Support}

This study was funded by the department of sport sciences, Ferdowsi University of Mashhad, Iran (Grant No 2/45972).

Acknowledgments

This article was extracted from a PhD thesis in Sports Physiology by Keyvan Hejazi in 2016 (No. IR.MUMS.REC.2016.131).

\section{References}

1. Li H, Zhang Y, Wang F, Donelan W, Zona MC, Li S, et al. Effects of irisin on the differentiation and browning of human visceral white adipocytes. Am J Transl Res. 2019;11(12):7410-21.

2. Karstoft K, Pedersen BK. Skeletal muscle as a gene regulatory endocrine organ. Curr Opin Clin Nutr Metab Care. 2016;19(4):270-5. doi: 10.1097/mco.0000000000000283.

3. Tine Kartinah N, Rosalyn Sianipar I, Nafi'ah, Rabia. The effects of exercise regimens on irisin levels in obese rats model: comparing high-intensity intermittent with continuous moderate-intensity training. Biomed Res Int. 2018;2018:4708287. doi: 10.1155/2018/4708287.

4. Islam H, Hood DA, Gurd BJ. Looking beyond PGC-1 $\alpha$ : emerging regulators of exercise-induced skeletal muscle mitochondrial biogenesis and their activation by dietary compounds. Appl Physiol Nutr Metab. 2020;45(1):11-23. doi: 10.1139/apnm-2019-0069.

5. Kalinkovich A, Livshits G. Sarcopenic obesity or obese sarcopenia: a cross talk between age-associated adipose tissue and skeletal muscle inflammation as a main mechanism of the pathogenesis. Ageing Res Rev. 2017;35:200-21. doi: 10.1016/j.arr.2016.09.008.

6. Chan MC, Arany Z. The many roles of PGC- $1 \alpha$ in muscle-- 
recent developments. Metabolism. 2014;63(4):441-51. doi: 10.1016/j.metabol.2014.01.006.

7. Boström P, Wu J, Jedrychowski MP, Korde A, Ye L, Lo JC, et al. A PGC1- $\alpha$-dependent myokine that drives brown-fatlike development of white fat and thermogenesis. Nature. 2012;481(7382):463-8. doi: 10.1038/nature10777.

8. Benusic M, Cheskin LJ. Obesity prevalence in large US cities: association with socioeconomic indicators, race/ethnicity and physical activity. J Public Health (Oxf). 2019. doi: 10.1093/ pubmed/fdz077.

9. Haegele JA, Aigner CJ, Healy S. Physical activity, body mass index, and health status among youth with severe visual impairments aged 13-17 years in the United States. Disabil Health J. 2019;12(1):24-8. doi: 10.1016/j.dhjo.2018.07.001.

10. Seo DY, Kwak HB, Lee SR, Cho YS, Song IS, Kim N, et al. Effects of aged garlic extract and endurance exercise on skeletal muscle FNDC-5 and circulating irisin in high-fat-diet rat models. Nutr Res Pract. 2014;8(2):177-82. doi: 10.4162/ nrp.2014.8.2.177.

11. Kurdiova T, Balaz M, Vician M, Maderova D, Vlcek M, Valkovic $\mathrm{L}$, et al. Effects of obesity, diabetes and exercise on Fndc5 gene expression and irisin release in human skeletal muscle and adipose tissue: in vivo and in vitro studies. J Physiol. 2014;592(5):1091-107. doi: 10.1113/jphysiol.2013.264655.

12. Brenmoehl J, Albrecht E, Komolka K, Schering L, Langhammer $\mathrm{M}$, Hoeflich A, et al. Irisin is elevated in skeletal muscle and serum of mice immediately after acute exercise. Int J Biol Sci. 2014;10(3):338-49. doi: 10.7150/ijbs.7972.

13. Hoshino D, Yoshida $Y$, Kitaoka $Y$, Hatta $H$, Bonen $A$. High-intensity interval training increases intrinsic rates of mitochondrial fatty acid oxidation in rat red and white skeletal muscle. Appl Physiol Nutr Metab. 2013;38(3):326-33. doi: 10.1139/apnm-2012-0257.

14. Shirvani H, Aslani J. The effects of high-intensity interval training vs. moderate-intensity continuous training on serum irisin and expression of skeletal muscle PGC- $1 \alpha$ gene in male rats. Tehran Univ Med J. 2017;75(7):513-20. [Persian].

15. Lee S, Farrar RP. Resistance training induces muscle-specific changes in muscle mass and function in rat. J Exerc Physiol Online. 2003;6(2):80-7.

16. Talebi Garekani E, Mohebbi H, Kraemer RR, Fathi R. Exercise training intensity/volume affects plasma and tissue adiponectin concentrations in the male rat. Peptides. 2011;32(5):1008-12. doi: 10.1016/j.peptides.2011.01.027.

17. Dong W, Quo W, Wang F, Li C, Xie Y, Zheng X, et al. Electroacupuncture upregulates SIRT1-dependent PGC-1 $\alpha$ expression in SAMP8 mice. Med Sci Monit. 2015;21:335662. doi: $10.12659 / \mathrm{msm} .894864$.

18. Uguccioni G, Hood DA. The importance of PGC- $1 \alpha$ in contractile activity-induced mitochondrial adaptations. Am J Physiol Endocrinol Metab. 2011;300(2):E361-71. doi: 10.1152/ajpendo.00292.2010.

19. Olusi SO. Obesity is an independent risk factor for plasma lipid peroxidation and depletion of erythrocyte cytoprotectic enzymes in humans. Int J Obes Relat Metab Disord. 2002;26(9):1159-64. doi: 10.1038/sj.ijo.0802066.

20. Park JS, Holloszy JO, Kim K, Koh JH. Exercise training-induced PPAR $\beta$ increases PGC- $1 \alpha$ protein stability and improves insulin-induced glucose uptake in rodent muscles. Nutrients. 2020;12(3). doi: 10.3390/nu12030652.

21. Little JP, Safdar A, Wilkin GP, Tarnopolsky MA, Gibala MJ. A practical model of low-volume high-intensity interval training induces mitochondrial biogenesis in human skeletal muscle: potential mechanisms. J Physiol. 2010;588(Pt 6):1011-22. doi: 10.1113/jphysiol.2009.181743.
22. Handschin C, Chin S, Li P, Liu F, Maratos-Flier E, Lebrasseur $\mathrm{NK}$, et al. Skeletal muscle fiber-type switching, exercise intolerance, and myopathy in PGC-1alpha muscle-specific knock-out animals. J Biol Chem. 2007;282(41):30014-21. doi: 10.1074/jbc.M704817200.

23. Moosavi R, Nazarali P, Kazemi F. Effects of eight weeks of TRX training on serum levels of PGC-1 $\alpha$ and citrate synthase in overweight women. Tehran Univ Med J. 2020;77(11):707-14. [Persian].

24. de Oliveira Bristot VJ, de Bem Alves AC, Cardoso LR, da Luz Scheffer D, Aguiar AS Jr. The role of PGC-1 $/$ /UCP2 signaling in the beneficial effects of physical exercise on the brain. Front Neurosci. 2019;13:292. doi: 10.3389/fnins.2019.00292.

25. Thornton SM, Krolopp JE, Abbott MJ. IL-15 mediates mitochondrial activity through a PPARS-dependent-PPAR $\alpha$ independent mechanism in skeletal muscle cells. PPAR Res. 2016;2016:5465804. doi: 10.1155/2016/5465804.

26. Gu X, Cai Z, Cai M, Liu K, Liu D, Zhang Q, et al. AMPK/ SIRT1/p38 MAPK signaling pathway regulates alcoholinduced neurodegeneration by resveratrol. Mol Med Rep. 2018;17(4):5402-8. doi: 10.3892/mmr.2018.8482.

27. Pardo PS, Boriek AM. The physiological roles of Sirt1 in skeletal muscle. Aging (Albany NY). 2011;3(4):430-7. doi: 10.18632/aging.100312.

28. Huh JY, Panagiotou G, Mougios V, Brinkoetter M, Vamvini MT, Schneider BE, et al. FNDC5 and irisin in humans: I. Predictors of circulating concentrations in serum and plasma and II. mRNA expression and circulating concentrations in response to weight loss and exercise. Metabolism. 2012;61(12):172538. doi: 10.1016/j.metabol.2012.09.002.

29. Abdi A, Mehrabani J, Nordvall M, Wong A, Fallah A, Bagheri R. Effects of concurrent training on irisin and fibronectin type-III domain containing 5 (FNDC5) expression in visceral adipose tissue in type-2 diabetic rats. Arch Physiol Biochem. 2020:1-6. doi: 10.1080/13813455.2020.1716018.

30. Lecker SH, Zavin A, Cao P, Arena R, Allsup K, Daniels KM, et al. Expression of the irisin precursor FNDC5 in skeletal muscle correlates with aerobic exercise performance in patients with heart failure. Circ Heart Fail. 2012;5(6):812-8. doi: 10.1161/ circheartfailure.112.969543.

31. Norheim F, Langleite TM, Hjorth M, Holen T, Kielland A, Stadheim HK, et al. The effects of acute and chronic exercise on PGC- $1 \alpha$, irisin and browning of subcutaneous adipose tissue in humans. Febs j. 2014;281(3):739-49. doi: 10.1111/ febs.12619.

32. Teimourian M, Fatolahi H, Mateenhomaei H. Effect of different exercise mode and ursolic acid supplementation on FNDC5 and UCP1 gene expression and plasma irisin in rats. Int J Sports Exerc Med. 2020;6(1):160. doi: 10.23937/24695718/1510160.

33. Nedergaard J, Cannon B. The browning of white adipose tissue: some burning issues. Cell Metab. 2014;20(3):396-407. doi: 10.1016/j.cmet.2014.07.005.

34. Ringholm S, Grunnet Knudsen J, Leick L, Lundgaard A, Munk Nielsen M, Pilegaard H. PGC- $1 \alpha$ is required for exercise- and exercise training-induced UCP1 up-regulation in mouse white adipose tissue. PLoS One. 2013;8(5):e64123. doi: 10.1371/ journal.pone.0064123.

35. Trayhurn P. Brown adipose tissue-a therapeutic target in obesity? Front Physiol. 2018;9:1672. doi: 10.3389/ fphys.2018.01672.

36. Cypess AM, Haft CR, Laughlin MR, Hu HH. Brown fat in humans: consensus points and experimental guidelines. Cell Metab. 2014;20(3):408-15. doi: 10.1016/j.cmet.2014.07.025. 